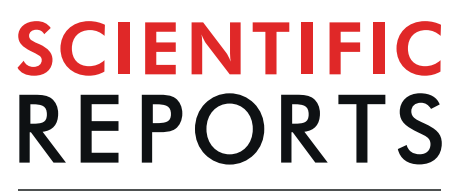

natureresearch

\title{
OPEN Two Hybrid Au-ZnO Heterostructures with Different Hierarchical Structures: Towards Highly Efficient Photocatalysts
}

\author{
Shuo Yang ${ }^{1,3,6}$, Lijing Wang ${ }^{2,6}$, Yongsheng Yan ${ }^{1}$, LiliYang ${ }^{1}$, Xin Li ${ }^{1}$, Ziyang Lu ${ }^{1}$, Hongju Zhai ${ }^{5}$,
} Donglai Han ${ }^{4 *}$ \& Pengwei Huo ${ }^{1^{*}}$

A new paradigm for photocatalysts based on two different hierarchically structured honeycomb and porous cylindrical Au-ZnO heterostructures was successfully developed via a straightforward and cost-effective hydrothermal method under different preparation conditions, which can be promising for industrial applications. The photocatalytic performance of all as-prepared samples under the illumination of sunlight was evaluated by the photocatalytic degradation of rhodamine B (RhB) and malachite green (MG) aqueous solutions. The results show that the photocatalytic degradation efficiency of $\mathrm{RhB}$ and $\mathrm{MG}$ was $55.3 \%$ and $\mathbf{4 0 . 7 \%}$ for $\mathrm{ZnO}, 95.3 \%$ and $\mathbf{9 3 . 4 \%}$ for the porous cylindrical Au$\mathrm{ZnO}$ heterostructure, and $\mathbf{9 8 . 6 \%}$ and $99.5 \%$ for the honeycomb Au-ZnO heterostructure, respectively. Compared with those from the $\mathrm{ZnO}$, the results herein demonstrate an excellent reduction in the photoluminescence and improvement in the photocatalysis for the Au-ZnO hybrids with different morphologies. These results were attributed not only to the greatly improved sunlight utilization efficiency due to the surface plasmon resonance (SPR) absorption of Au nanoparticles in the visible region coupled with the UV light utilization by the $\mathrm{ZnO}$ nanostructures and multi-reflections of the incident light in the pore structures of their interior cavities but also to the high charge separation efficiency and low Schottky barrier generated by the combination of Au nanoparticles and ZnO micromaterials. Moreover, the honeycomb Au-ZnO heterostructure had a high Au content, surface area and surface oxygen vacancy $\left(\mathrm{O}_{\mathrm{v}}\right)$, which enabled photocatalytic properties that were higher than those of the porous cylindrical Au-ZnO heterostructures. In addition, two different formation mechanisms for the morphology and possible photocatalytic mechanisms are proposed in this paper.

Sunlight-driven semiconductor-based heterogeneous photocatalysts have been extensively investigated due to their straightforward operation, environmental friendliness and high efficiency ${ }^{1-3}$. Thus, different semiconductors have been explored to improve their cost-efficiency, long-term stability and efficiency ${ }^{4-6}$. Among these, $\mathrm{ZnO}$ stands out due to its excellent characteristics, e.g., a direct wide band gap $(\mathrm{Eg}=3.37 \mathrm{eV})$, good availability, cost effectiveness, low-toxicity, unique acoustic and optoelectronic properties, chemical stability and nanoscale tunability $^{7-12}$. Nevertheless, the wide bandgap energy of $\mathrm{ZnO}$ allows the generation of excitons only upon UV light irradiation, which is less than $5 \%$ of the solar spectrum, hence limiting its performance as a solar photocatalyst. The relatively high recombination rate of photogenerated electron-hole pairs also greatly reduces the efficiency of $\mathrm{ZnO}$ photocatalysts ${ }^{13-15}$.

\footnotetext{
${ }^{1}$ School of Chemistry \& Chemical Engineering, Jiangsu University, Zhenjiang, 212013, P.R. China. ${ }^{2}$ Henan engineering center of new energy battery materials, Henan D\&A engineering center of advanced battery materials, College of Chemistry and Chemical Engineering, Shangqiu Normal University, Shangqiu, 476000, P.R. China. ${ }^{3}$ Changchun Institute of Optics, Fine Mechanics and Physics, Chinese Academy of Sciences, Changchun, 130033, P.R. China. ${ }^{4}$ School of Materials Science and Engineering, Changchun University of Science and Technology, Changchun, 130022, P.R. China. ${ }^{5}$ Key Laboratory of Preparation and Applications of Environmentally Friendly Materials of the Ministry of Education, Jilin Normal University, Siping, 136000, Jilin Province, P.R. China. ${ }^{6}$ These authors contributed equally: Shuo Yang and Lijing Wang. *email: DLHan_1015@163.com; 1819498875@qq.com
} 
To overcome the aforementioned drawbacks, a workable solution to improve the optical absorption capacity and reduce charge recombination of $\mathrm{ZnO}$ is desired. It is well known that noble metals have desirable properties, such as surface plasmon resonance, straightforward reduction, chemical stability and bio-affinity ${ }^{16-20}$. Among them, Au nanoparticles show excellent SPR properties and charge storage capability ${ }^{21}$. When $\mathrm{ZnO}$ is combined with Au nanoparticles, the Schottky barrier at the $\mathrm{Au}-\mathrm{ZnO}$ interface can effectively separate the photogenerated charge $e^{4,15,22,23}$. In other words, a $\mathrm{ZnO}$ semiconductor combined with plasmonic Au nanoparticles can substantially enhance the photocatalytic degradation efficiency of organic pollutants ${ }^{17,24,25}$. The performance of $\mathrm{Au}-\mathrm{ZnO}$ heterostructures largely depends on their preparation method, particle size and morphology ${ }^{26}$. However, the current synthesis methods of $\mathrm{Au}-\mathrm{ZnO}$ catalysts, including deposition precipitation ${ }^{27}$, co-precipitation ${ }^{28}$, microwave-assisted chemical synthesis ${ }^{29}$, one-pot non-aqueous synthesis ${ }^{30}$ and photodeposition ${ }^{31}$, fail to meet all the needs of cost-efficiency and easy-operation. Moreover, the reported morphologies of Au- $\mathrm{ZnO}$ catalysts, including nanorods ${ }^{32}$, nanopyramids ${ }^{33}$, petal-like structures, urchin-like nanoflowers, nanomultipods, nanopyramids $^{30}$ and hollow doughnut-like Au-ZnO catalysts ${ }^{29}$, are too complicated for ordinary laboratory research and industrial applications. To address this issue, we proposed a straightforward, cost-effective and uncomplicated hydrothermal method to synthesize $\mathrm{Au}-\mathrm{ZnO}$ heterostructures. To further investigate the influence of $\mathrm{Au}-\mathrm{ZnO}$ structure morphologies on the growth scheme, photoluminescence and photocatalytic performance, honeycomb and porous cylindrical-like $\mathrm{Au}-\mathrm{ZnO}$ heterostructures were fabricated by adjusting the $\mathrm{pH}$. The new $\mathrm{Au}-\mathrm{ZnO}$ heterostructures not only were uncomplicated, inexpensive and easy to synthesize but also showed decreased PL intensity and enhanced degradation efficiency, which can be promising for cost-efficient and uncomplicated ordinary laboratory research and industrial applications.

\section{Experimental Methods}

Materials. All precursors, including chloroauric acid $\left(\mathrm{HAuCl}_{4}\right)$, sodium borohydride $\left(\mathrm{NaBH}_{4}\right)$, ethylene glycol (EG), zinc acetate dihydrate $\left(\mathrm{Zn}\left(\mathrm{CH}_{3} \mathrm{COO}\right)_{2} \cdot 2 \mathrm{H}_{2} \mathrm{O}\right)$, hexamethylene tetramine $\left(\mathrm{C}_{6} \mathrm{H}_{12} \mathrm{~N}_{4}, \mathrm{HMT}\right)$, sodium hydroxide $(\mathrm{NaOH})$ and rhodamine $\mathrm{B}(\mathrm{RhB})$, were analytical grade and purchased from Guangdong Chemical Reagent Co. without further purification.

Preparation of the honeycomb-like $\mathrm{Au}-\mathrm{ZnO}$ heterostructure. First, Au particles were prepared by dispersing $0.01 \mathrm{mmol} \mathrm{NaBH}_{4}$ into $0.01 \mathrm{mmol} \mathrm{HAuCl}_{4}$ under continuous stirring until the aqueous solution turned wine red and divided into two equal parts. Second, $0.04 \mathrm{mmol} \mathrm{Zn}\left(\mathrm{CH}_{3} \mathrm{COO}\right)_{2} \cdot 2 \mathrm{H}_{2} \mathrm{O}$ and $0.02 \mathrm{mmol} \mathrm{HMT}$ were added into $40 \mathrm{~mL}$ EG. After half an hour, the solution fully reacted and formed white curds; it was then mixed with the Au particles under stirring at room temperature for $2 \mathrm{~h}$. Third, the obtained product was transferred into a Teflon-lined autoclave $(18 \mathrm{~mL})$ and heated in an oven at $100^{\circ} \mathrm{C}$ for $8 \mathrm{~h}$. After that, the autoclave was cooled naturally to room temperature, and then the sample was repeatedly washed with ethanol to remove any ionic residuals. After drying the sample at $80^{\circ} \mathrm{C}$ for $24 \mathrm{~h}$, the honeycomb Au-ZnO heterostructure was finally obtained and kept for further characterization.

Preparation of the porous cylindrical-like Au-ZnO heterostructure. First, by adding $0.04 \mathrm{mmol}$ $\mathrm{Zn}\left(\mathrm{CH}_{3} \mathrm{COO}\right)_{2} \cdot 2 \mathrm{H}_{2} \mathrm{O}$ and $0.02 \mathrm{mmol} \mathrm{NaOH}$ to $40 \mathrm{~mL} \mathrm{EG}$, we obtained pure $\mathrm{ZnO}$ after heating the solution to $100^{\circ} \mathrm{C}$ for $8 \mathrm{~h}$. Then, part of pure $\mathrm{ZnO}$ was kept for future characterization, and the rest was used to prepare the honeycomb Au-ZnO heterostructure. The remaining steps were the same as those for preparing the honeycomb $\mathrm{Au}-\mathrm{ZnO}$ heterostructures.

Photocatalytic organic degradation. The photocatalytic activities of the obtained samples were measured by the degradation of the $\mathrm{RhB}$, methyl orange and malachite green aqueous solutions under simulated sunlight. A $500 \mathrm{~W}$ Xe lamp with a maximum intensity of $494 \mathrm{~nm}$ was used. The pure $\mathrm{ZnO}$ and honeycomb and porous cylindrical-like $\mathrm{Au}-\mathrm{ZnO}$ heterostructures were immersed into the $\mathrm{RhB}$ and $\mathrm{MG}$ aqueous solution for $30 \mathrm{~min}$ in the dark to reach an adsorption-desorption equilibrium between the catalysts and RhB and MG molecules, respectively. In a typical experiment, $0.1 \mathrm{~g}$ of the sample was added to $100 \mathrm{~mL}$ of $10 \mathrm{mg} \cdot \mathrm{L}^{-1}$ organic dye solution. After that, the light source was switched on, and then $2 \mathrm{~mL}$ aliquots were withdrawn from every irradiated suspension after $4 \mathrm{~min}$. Then, the concentrations of the RhB and MG were analysed by a UV-Vis spectrophotometer with a distance of $14 \mathrm{~cm}$ between the cuvettes and the light source, the absorption spectra were obtained, and the percentage degradation values were calculated.

Sample characterization. X-ray powder diffraction (XRD) analysis was performed (Rigaku D/max-ga, Japan) at $40 \mathrm{kV}$ and $100 \mathrm{~mA}$ and with a Cu radiation source to explore the composition and crystalline properties of the Au- $\mathrm{ZnO}$ heterostructures. The scanning speed was $10^{\circ} \mathrm{min}^{-1}$ from $10^{\circ}$ to $80^{\circ}$. Scanning electron microscopy (SEM) images were taken on a LEO-1530VP field-emission scanning electron microscope. High-resolution transmission electron (HRTEM) micrographs and energy dispersive X-ray (EDX) analysis was conducted on a JEOL-2010 high-resolution transmission electron microscope with an accelerating voltage of $220 \mathrm{kV}$. X-ray photoelectron spectroscopy (XPS) was performed on an ESCALAB 250 (Thermo Scientific, Grand Island, NY, USA) with a monochromatized Al K X-ray source $(1486.6 \mathrm{eV})$ and $500 \mu \mathrm{m}$ spot size. Photoluminescence (PL) spectra were measured at room temperature at an excitation wavelength of $325 \mathrm{~nm}$, and UV-vis absorption spectra were explored on a TU-1901 spectrophotometer. The BET specific surface areas were measured at $-196^{\circ} \mathrm{C}$ using an ASAP 2010 analyser (Micromeritics, Norcross, GA, USA). 


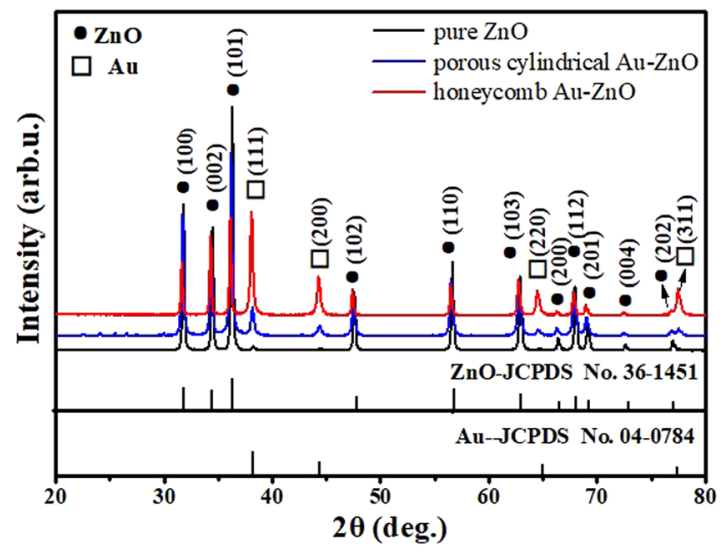

Figure 1. XRD patterns of pure $\mathrm{ZnO}$ (black line) and honeycomb (red line) and porous cylindrical (blue line) $\mathrm{Au}-\mathrm{ZnO}$ heterostructures.

\section{Results and Discussion}

Figure 1 presents the XRD patterns of the as-prepared pure $\mathrm{ZnO}$ (black line) and honeycomb (red line) and porous cylindrical (blue line) $\mathrm{Au}-\mathrm{ZnO}$ heterostructures. As seen for the black line in Fig. 1, all the diffraction peaks observed at $2 \theta$ values of $31.7^{\circ}, 34.4^{\circ}, 36.2^{\circ}, 47.5^{\circ}, 56.6^{\circ}, 62.9^{\circ}, 66.3^{\circ}, 67.9^{\circ}, 69.1^{\circ}, 72.6^{\circ}$, and $76.9^{\circ}$ matched well to the (100), (002), (101), (102), (110), (103), (200), (112), (201), (004) and (202) planes, respectively, for hexagonal wurtzite $\mathrm{ZnO}$ (JCPDS card No. 36-1451) ${ }^{34}$. As the XRD patterns of the honeycomb and porous cylindrical $\mathrm{Au}-\mathrm{ZnO}$ samples showed, the diffraction peaks (except for that from $\mathrm{ZnO}$ ) observed at $2 \theta$ values of $38.1^{\circ}, 44.2^{\circ}$, $64.5^{\circ}$ and $77.5^{\circ}$ were indexed to the (111), (200), (220) and (311) planes, respectively, for cubic phase Au (JCPDS No. 04-0784) $)^{35}$. No characteristic peaks of other impurities were detected, indicating that the films were prepared as intended. In addition, the Au peak intensity from the honeycomb $\mathrm{Au}-\mathrm{ZnO}$ was stronger than that from the porous cylindrical-like $\mathrm{Au}-\mathrm{ZnO}$ heterostructures, indicating that the $\mathrm{Au}$ content in honeycomb-like $\mathrm{Au}-\mathrm{ZnO}$ heterostructures was higher than that in cylindrical-like $\mathrm{Au}-\mathrm{ZnO}$ heterostructures.

The morphology evolution was investigated with SEM and BET tests were carried out to observe the amount of Au nanoparticles, morphology and specific surface area of the honeycomb and porous cylindrical $\mathrm{Au}-\mathrm{ZnO}$ heterostructures. Figure 2(a) shows an SEM image of the honeycomb-like Au-ZnO heterostructure. Au nanoparticles were uniformly distributed across the $\mathrm{ZnO}$ surface, and the $\mathrm{Au}-\mathrm{ZnO}$ heterostructure consisted of many hollow structures with an outer diameter of $5 \mu \mathrm{m}$ and an inner diameter of approximately $150 \mathrm{~nm}$. Figure 2(c) shows an SEM image of the porous cylindrical-like Au-ZnO heterostructure, which contains a block-like structure with many small holes. The $\mathrm{N}_{2}$ adsorption-desorption isotherms of the honeycomb and porous cylindrical $\mathrm{Au}-\mathrm{ZnO}$ heterostructures are presented in Fig. 2(b,d), respectively. The isotherms of the two samples exhibited the characteristics of type $\mathrm{H} 3$ hysteresis loops based on the Brunauer-Deming-Deming-Teller (BDDT) classification for a high relative pressure between 0.4 and $1.0^{36}$. The analyses show that the BET specific surface area of the honeycomb and porous cylindrical $\mathrm{Au}-\mathrm{ZnO}$ heterostructures was 20.73 and $10.08 \mathrm{~m}^{2} \cdot \mathrm{g}^{-1}$, respectively. In addition, the average pore size for the honeycomb and porous cylindrical $\mathrm{Au}-\mathrm{ZnO}$ heterostructures was approximately 23.89 and $16.13 \mathrm{~nm}$, respectively. In comparison to that of the porous cylindrical $\mathrm{Au}-\mathrm{ZnO}$, the pore size of the honeycomb Au- $\mathrm{ZnO}$ were smaller, which resulted in a high amount of exposed surface area and increased absorption of the solar light. This publication also suggested that pore structures could allow multi-reflections of light radiation in their interior cavities, leading to enhanced light harvesting and photocatalytic activity ${ }^{37}$.

To further identify the morphology and detailed structure of the $\mathrm{Au}-\mathrm{ZnO}$ heterostructures and reveal their chemical element composition, HRTEM and EDX analyses of the honeycomb (Fig. 3a,b) and porous cylindrical $\mathrm{Au}-\mathrm{ZnO}$ heterostructures (Fig. 3c,d) were carried out. As shown in Fig. 3(a,c), the distance between two adjacent planes in wurtzite $\mathrm{ZnO}$ was determined to be $0.248 \mathrm{~nm}$ (honeycomb) and $0.28 \mathrm{~nm}$ (porous cylindrical), corresponding to the (101) and (100) planes of $\mathrm{ZnO}$, respectively. These crystal planes had clear fringes, and the shades between them varied, indicating the formation of the $\mathrm{Au}-\mathrm{ZnO}$ heterostructures. Additionally, the EDX spectra of the honeycomb (Fig. 3b) and porous cylindrical (Fig. 3d) structures were obtained to determine their chemical composition. The analysis results showed that both structures contained $\mathrm{Zn}, \mathrm{Au}$, and $\mathrm{O}$ elements, which clearly indicated the formation of $\mathrm{Au}-\mathrm{ZnO}$ heterostructures. The concentration of $\mathrm{Au}$ particles in the honeycomb heterostructure (Fig. 3b) was higher than that of the porous cylindrical Au-ZnO heterostructure (Fig. 3d), which is consistent with the XRD and SEM results.

XPS measurements were performed to investigate the surface elemental composition and elemental valences of the honeycomb (Fig. $4 \mathrm{a}-\mathrm{d}$ ) and porous cylindrical Au- $\mathrm{ZnO}$ heterostructures (Fig. 4e-h). All binding energy values in the XPS spectra were calibrated according to the information for $\mathrm{C} 1 \mathrm{~s}(284.6 \mathrm{eV})^{38}$. The presence of C mainly originated from the oil pump due to the vacuum treatment ${ }^{39}$. In the survey spectra of the honeycomb and porous cylindrical $\mathrm{Au}-\mathrm{ZnO}$ heterostructures (Fig. 4a,e, respectively), all elements, namely, $\mathrm{Au}, \mathrm{O}$ and $\mathrm{Zn}$, were detected with strong characteristic peaks. The $\mathrm{O} 1 \mathrm{~s}$ peaks were fitted into three peaks located at 530.1, 531.0, and $532.0 \mathrm{eV}$, as shown in Fig. 4c,g, indicating three different kinds of oxygen species in both the honeycomb and porous cylindrical $\mathrm{Au}-\mathrm{ZnO}$ heterostructures. The oxygen peak at $532.0 \mathrm{eV}$ was ascribed to lattice oxygen $\left(\mathrm{O}_{\mathrm{L}}\right)$ in 

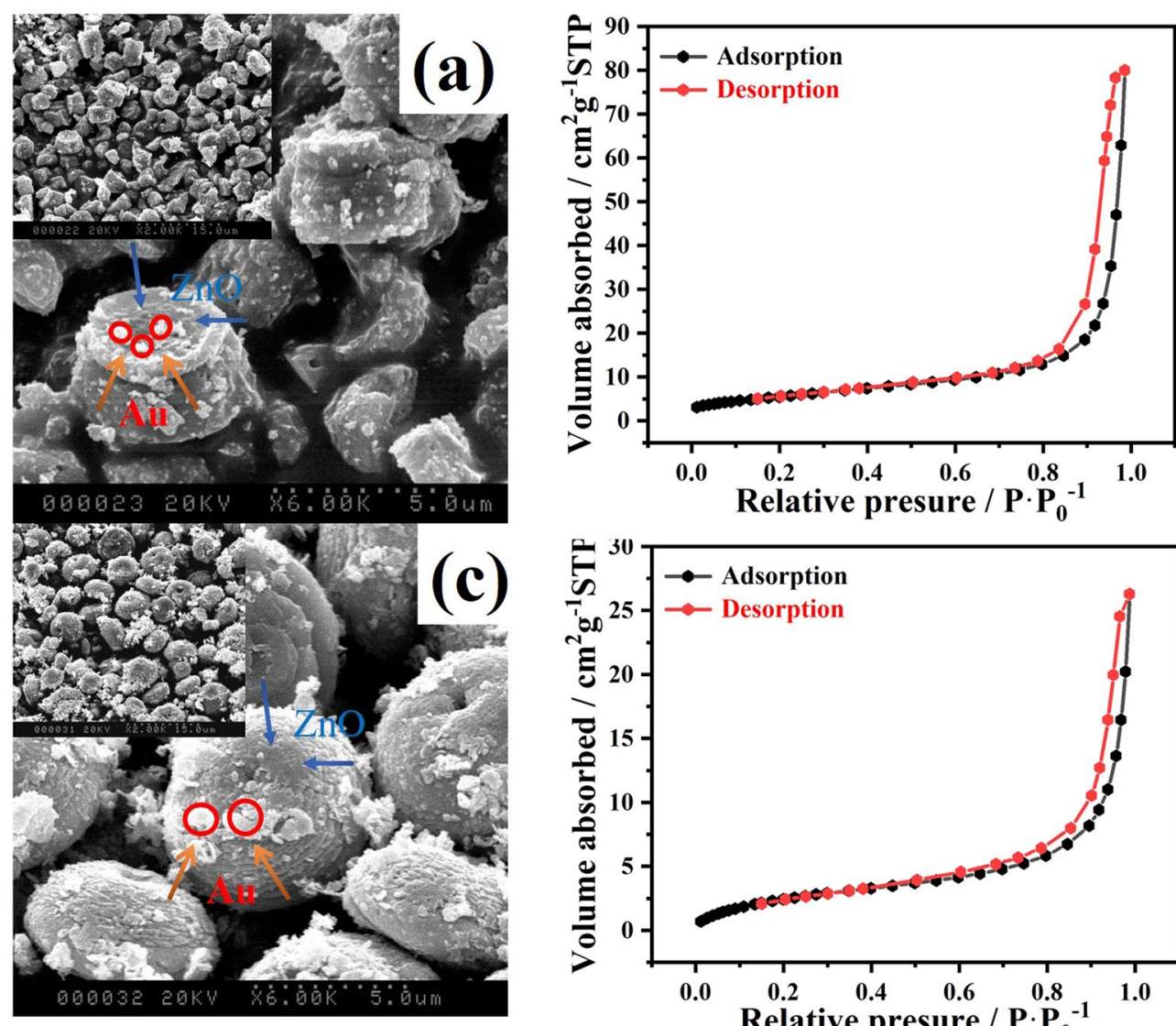

(b)

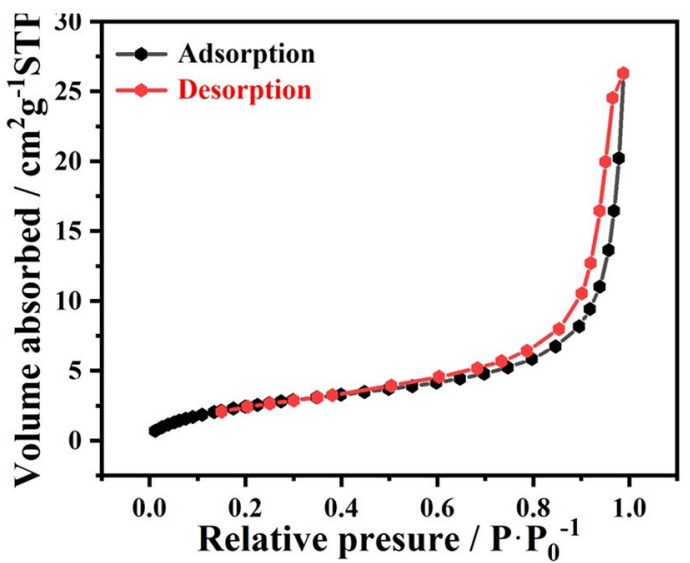

(d)

Figure 2. (a) SEM image and (b) BET plot for the honeycomb Au-ZnO heterostructures, and (c) SEM image and (d) BET plot for the porous cylindrical $\mathrm{Au}-\mathrm{ZnO}$ heterostructures.
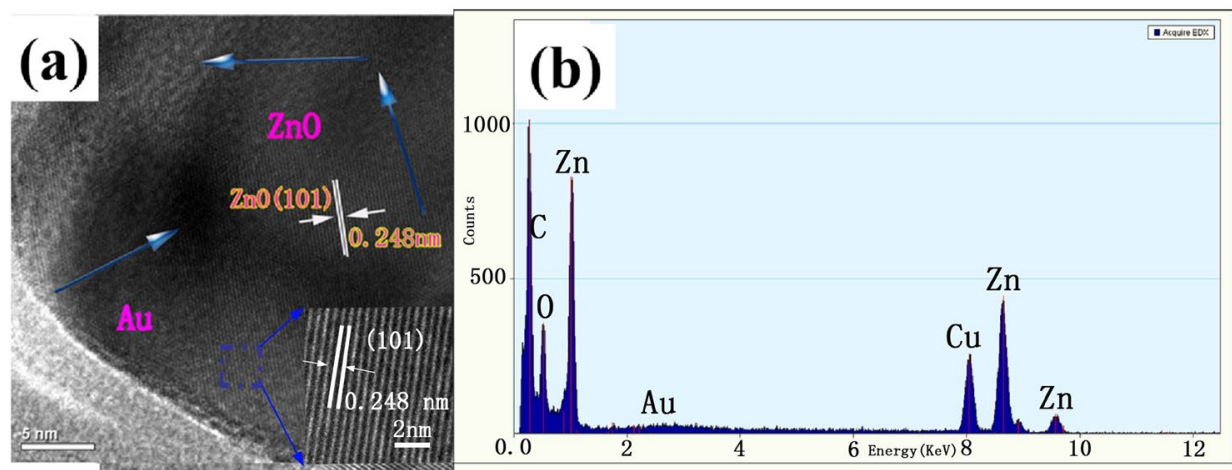

(c)

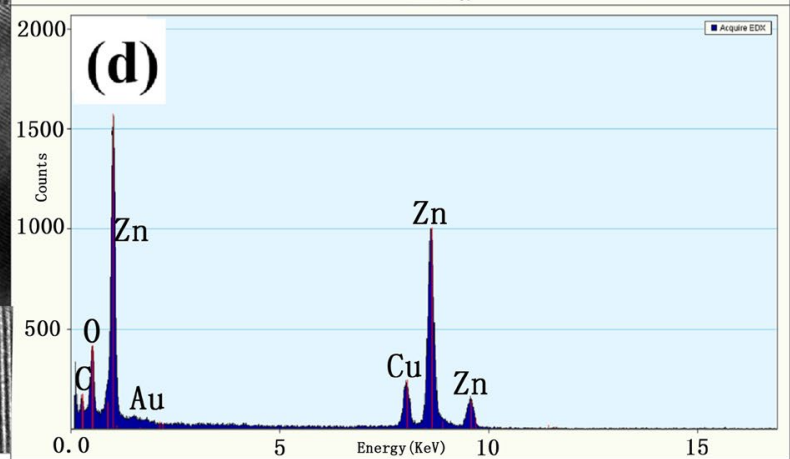

Figure 3. (a) HRTEM, magnified HRTEM patterns and (b) EDX spectra of honeycomb Au-ZnO heterostructures and (c) HRTEM, magnified HRTEM patterns and (d) EDX spectra of porous cylindrical Au$\mathrm{ZnO}$ heterostructures. 

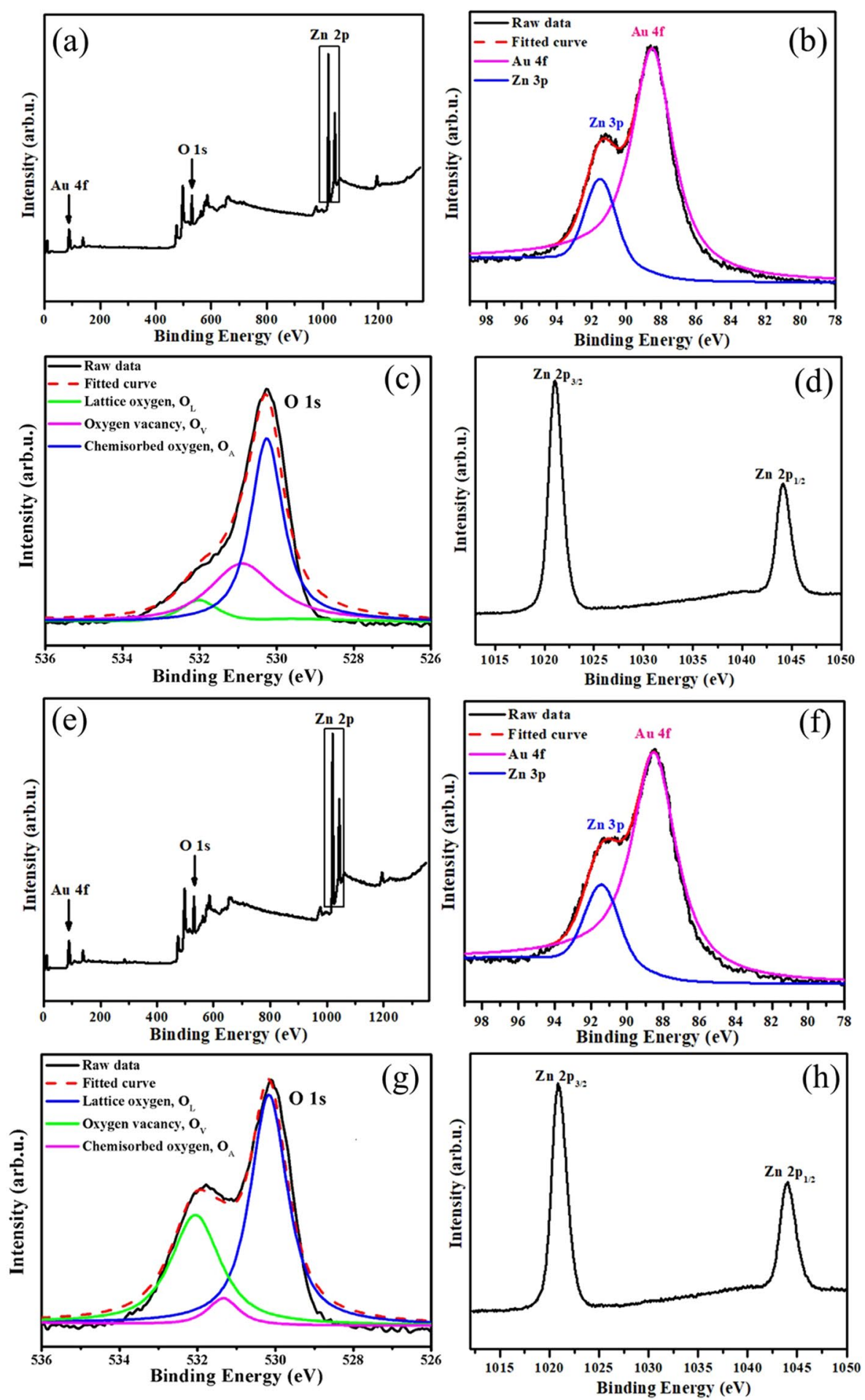

Figure 4. Data for (a-d) honeycomb and (e-h) porous cylindrical Au-ZnO heterostructures: XPS survey spectra (a,d) and high-resolution XPS spectra of Au $4 \mathrm{f}(\mathbf{b}, \mathbf{e}), \mathrm{O} 1 \mathrm{~s}(\mathbf{c}, \mathbf{g})$ and $\mathrm{Zn} 2 \mathrm{p}(\mathbf{d}, \mathbf{h})$.

the wurtzite structure that was surrounded by zinc atoms that had their full complement of nearest-neighbour $\mathrm{O}^{2-}$ ions. The medium oxygen peak at $531.0 \mathrm{eV}$ was ascribed to $\mathrm{O}^{2-}$ ions in oxygen vacancy $\left(\mathrm{O}_{\mathrm{v}}\right)$ regions within the $\mathrm{ZnO}$ matrix ${ }^{40}$. The oxygen peak at $530.1 \mathrm{eV}$ was attributed to chemisorbed oxygen $\left(\mathrm{O}_{\mathrm{A}}\right)$ caused by the surface hydroxyl groups $(\mathrm{O}-\mathrm{H} \text { bonds })^{40}$. Upon comparing Fig. 4c,g, the $\mathrm{O}_{\mathrm{v}}$ peak from the honeycomb Au- $\mathrm{ZnO}$ was stronger than that from the porous cylindrical $\mathrm{Au}-\mathrm{ZnO}$, which is consistent with the result that the photocatalytic performance of the honeycomb $\mathrm{Au}-\mathrm{ZnO}$ was better than that of the porous cylindrical $\mathrm{Au}-\mathrm{ZnO}{ }^{41}$. The $\mathrm{Zn}$ $2 \mathrm{p}$ regions in the XPS spectra (Fig. $4 \mathrm{~d}, \mathrm{~h}$ ) consisted of two peaks centred at $1021.9 \mathrm{eV}$ and $1044.9 \mathrm{eV}$, which are 


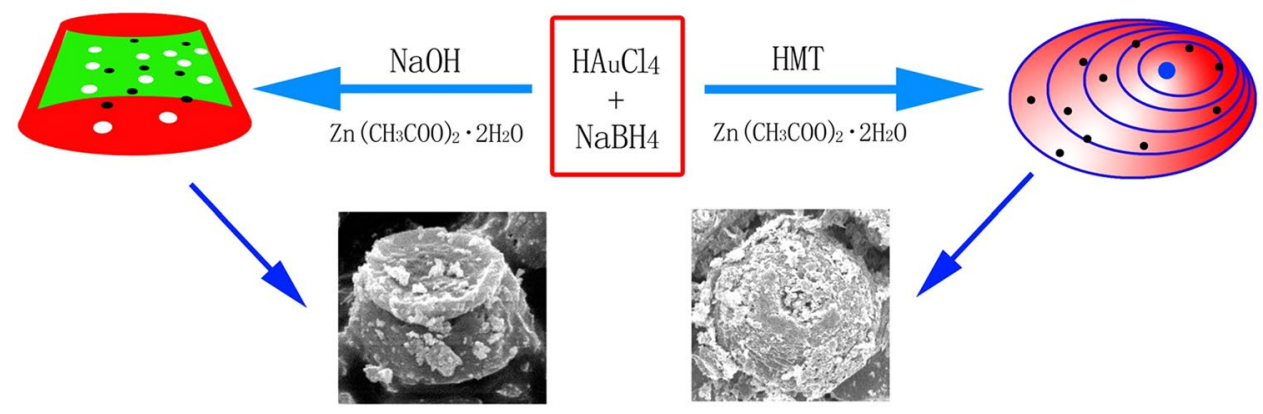

Figure 5. Scheme of the preparation of honeycomb and porous cylindrical $\mathrm{Au}-\mathrm{ZnO}$ heterostructures.

characteristic of $\mathrm{Zn} 2 \mathrm{p} 3 / 2$ and $\mathrm{Zn} 2 \mathrm{p} 1 / 2$ in $\mathrm{ZnO}^{42}$. The $\mathrm{Zn} 2 \mathrm{p}$ core level dipoles induced by spin-orbit coupling are typical of $\mathrm{ZnO}$ materials in terms of binding energy, peak shape and peak separation, which was $23 \mathrm{eV}^{43}$.

Based on the experimental results above, the synthesis scheme of the two $\mathrm{Au}-\mathrm{ZnO}$ heterostructures is presented in Fig. 5, which clearly describes the differences between the two samples during the preparation process. As discussed above, the Au concentration in the honeycomb Au- $\mathrm{ZnO}$ heterostructure was higher than that of the porous cylindrical $\mathrm{Au}-\mathrm{ZnO}$ heterostructure, which was closely related to the use of $\mathrm{NaOH}$. The honeycomb $\mathrm{Au}-\mathrm{ZnO}$ was prepared with HMT, while the porous cylindrical Au-ZnO was prepared with NaOH. HMT can effectively combine with $\mathrm{Zn}^{2+}$ and maintain $\mathrm{Zn}^{2+}$ at a low concentration. HMT can also coordinate to the $\mathrm{ZnO}$ crystal, obstructing the growth of certain surfaces ${ }^{44}$. According to previous systematic studies, HMT can control the morphology of different samples. Here, HMT acted as a $\mathrm{pH}$ buffer by slowly decomposing the $\mathrm{NH}_{3}$ and combining with the $\mathrm{Zn}^{2+}$ to form $\left[\mathrm{Zn}\left(\mathrm{NH}_{3}\right)_{4}\right]^{2+45}$, which resulted in the corrosion of the $\mathrm{ZnO}$ and the formation of a honeycomb Au- $\mathrm{ZnO}$ heterostructure. During the growth of the porous cylindrical $\mathrm{Au}-\mathrm{ZnO}$ heterostructures, the $\mathrm{NaOH}$ reacted with the $\mathrm{Zn}\left(\mathrm{CH}_{3} \mathrm{COO}\right)_{2} \cdot 2 \mathrm{H}_{2} \mathrm{O}$ to form $\mathrm{Zn}(\mathrm{OH})_{2}$ but decomposed to $\mathrm{ZnO}$ at high temperatures. However, the strong alkaline hydroxide may partially etch $\mathrm{ZnO}$ and cause the formation of $\left[\mathrm{Zn}(\mathrm{OH})_{4}\right]^{2-}$, which helped form the porous structure. It is believed that the porous cylindrical $\mathrm{Au}-\mathrm{ZnO}$ had a weaker corrosion degree than that of the honeycomb $\mathrm{Au}-\mathrm{ZnO}$. Thus, the honeycomb Au- $\mathrm{ZnO}$ heterostructure exhibited a higher concentration of $\mathrm{Au}$ and a larger surface area than that of the porous cylindrical $\mathrm{Au}-\mathrm{ZnO}$. The reaction equations are as follows ((1-4) for honeycomb $\mathrm{Au}-\mathrm{ZnO}$, while ( 1 and 5-7) is for porous cylindrical $\mathrm{Au}-\mathrm{ZnO})$ :

$$
\begin{gathered}
\mathrm{HAuCl}_{4} \stackrel{\mathrm{NaBH}_{4} \mathrm{Au}}{\longrightarrow} \\
\left(\mathrm{CH}_{2}\right)_{6} \mathrm{~N}_{4}+6 \mathrm{H}_{2} \mathrm{O} \rightarrow 4 \mathrm{NH}_{3}+6 \mathrm{HCHO} \\
\mathrm{Zn}^{2+}+2 \mathrm{NH}_{3}+2 \mathrm{H}_{2} \mathrm{O} \rightarrow \mathrm{Zn}(\mathrm{OH})_{2}+2 \mathrm{NH}_{4}^{+} \\
\mathrm{Zn}(\mathrm{OH})_{2}+4 \mathrm{NH}_{3} \rightarrow\left[\mathrm{Zn}\left(\mathrm{NH}_{3}\right)_{4}\right]^{2+}+2 \mathrm{OH}^{-} \\
\mathrm{NaOH}+\mathrm{Zn}\left(\mathrm{CH}_{3} \mathrm{COO}\right)_{2} \rightarrow \mathrm{Zn}(\mathrm{OH})_{2}+2 \mathrm{CH}_{3} \mathrm{COONa}^{2-} \\
\mathrm{Zn}(\mathrm{OH})_{2}+2 \mathrm{OH}{ }^{-} \rightarrow\left[\mathrm{Zn}(\mathrm{OH})_{4}\right]^{2-} \\
\mathrm{Zn}(\mathrm{OH})_{2} \rightarrow \mathrm{ZnO}+\mathrm{H}_{2} \mathrm{O}
\end{gathered}
$$

Figure 6 presents the PL spectra for the pure $\mathrm{ZnO}$ and $\mathrm{Au}-\mathrm{ZnO}$ heterostructures with different morphologies. Two $\mathrm{ZnO}$ peaks were detected, namely a sharp and narrow peak located at $380 \mathrm{~nm}$ and a low and broad peak at approximately $600 \mathrm{~nm}$; no peak was detected from the Au particles. Due to the influence of the Au particles, the peak intensity of $\mathrm{Au}-\mathrm{ZnO}$ heterostructure showed an obvious decrease in both the ultraviolet and visible light regions. The honeycomb $\mathrm{Au}-\mathrm{ZnO}$ heterostructure exhibited a lower peak intensity than that of the porous cylindrical $\mathrm{Au}-\mathrm{ZnO}$ heterostructure, and its peak in the visible region was slightly shifted to the right. Generally, the near-band ultraviolet emission of $\mathrm{ZnO}$ at approximately $380 \mathrm{~nm}$ is considered an exciton transition, while the emission peak between 520 and $600 \mathrm{~nm}$ is considered a deep-level emission caused by oxygen vacancies or $\mathrm{Zn}$ vacancy defects ${ }^{46}$. There are two possible reasons for the different emission intensities compared to those in the pure ZnO. First, the PL emission mainly results from the recombination of excited electrons and holes ${ }^{47}$. A decreased PL intensity indicates an increased separation efficiency, and the weak UV and visible emission intensity of the $\mathrm{Au}-\mathrm{ZnO}$ heterostructure indicates a lower recombination rate for the photoelectron carriers than that for pure $\mathrm{ZnO}$. This is due to the electrons excited from the valence band to the conduction band transfer to the Fermi level of $\mathrm{Au}$, thereby preventing the direct recombination of electrons and holes. Second, it has been reported that PL emission is affected by the number and size of Au nanoparticles ${ }^{48}$. When the number of Au nanoparticles increases or the size of Au nanoparticles surpasses an optimum value, the intensity of the near-band-edge emission is reduced. From the SEM images, we can see that the honeycomb $\mathrm{Au}-\mathrm{ZnO}$ possessed 


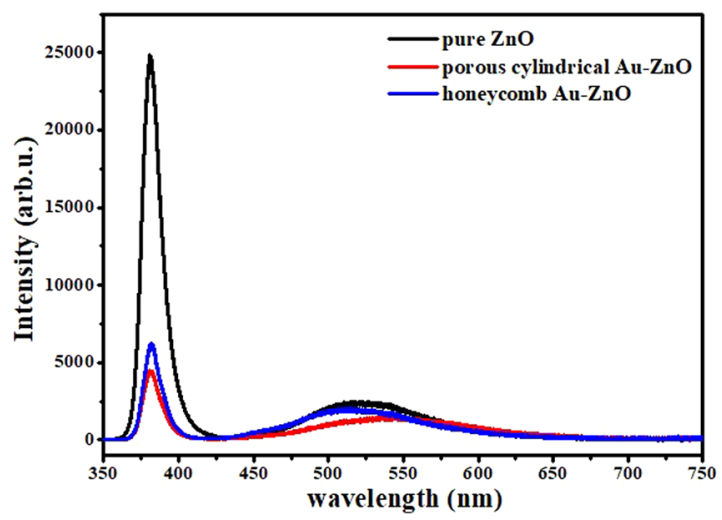

Figure 6. PL spectra of pure $\mathrm{ZnO}$ (black line) and honeycomb-like (red line) and porous cylindrical-like (blue line) $\mathrm{Au}-\mathrm{ZnO}$ heterostructures.
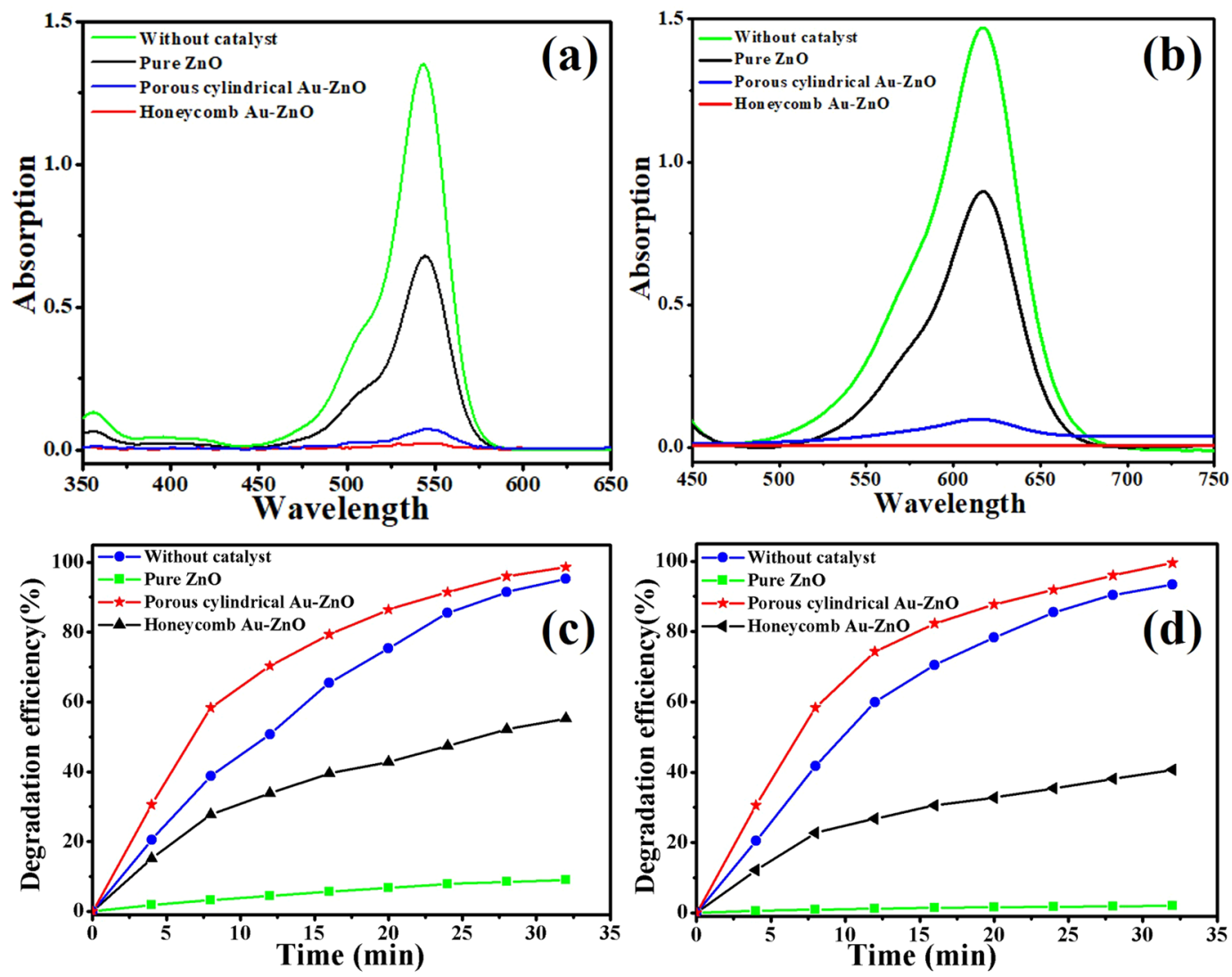

Figure 7. The absorption spectra and degradation efficiency as a function of time under simulated sunlight for the $\mathrm{RhB}(\mathbf{a}, \mathbf{c})$ and $\mathrm{MG}(\mathbf{b}, \mathbf{d})$ solutions without a sample (green line), with pure $\mathrm{ZnO}$ (black line) and with the honeycomb (red line) and porous cylindrical (blue line) $\mathrm{Au}-\mathrm{ZnO}$ heterostructures.

more $\mathrm{Au}$ nanoparticles with a larger mean diameter than those in the porous cylindrical $\mathrm{Au}-\mathrm{ZnO}$. The redshift was mainly attributed to the interfacial interaction between the $\mathrm{ZnO}$ and $\mathrm{Au}$, which might lead to a charge variation of the Au surface.

The photocatalytic activities of the pure $\mathrm{ZnO}$ and two $\mathrm{Au}-\mathrm{ZnO}$ heterostructures were investigated by degrading $\mathrm{RhB}$ and MG under simulated sunlight, and the corresponding UV-vis absorption spectra are shown in Fig. 7. From Fig. 7(a,b), we can see a strong absorption peak for RhB centred at approximately $550 \mathrm{~nm}$ and a strong absorption peak for MG centred at approximately $614 \mathrm{~nm}$. Without a catalyst, it hardly decreased within $32 \mathrm{~min}$, and the pure $\mathrm{ZnO}$ showed certain catalytic properties. In comparison, a distinct enhancement in the photocatalytic efficiencies was observed when using the $\mathrm{Au}-\mathrm{ZnO}$ heterostructure, with a rapid decrease of the main absorption peak intensity. It can be seen that the RhB and MG were almost fully degraded within $32 \mathrm{~min}$. The degradation rates of the RhB and MG are shown in Fig. 7c,d, respectively, which reveals their degradation 


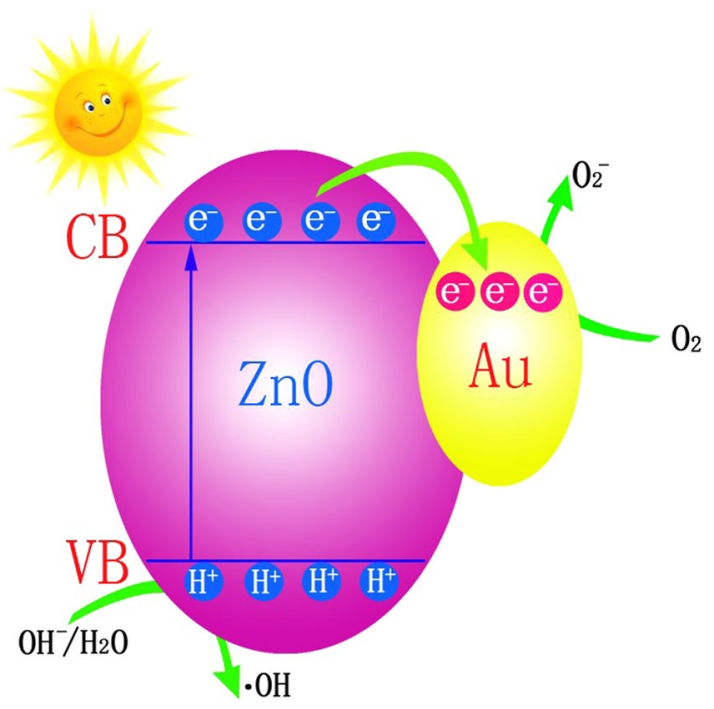

Figure 8. Mechanism for the degradation procedure of $\mathrm{RhB}$ with $\mathrm{Au}-\mathrm{ZnO}$ heterostructure catalysts.

efficiency clearly by comparing the photocatalytic activities of the three different catalysts: honeycomb (98.6\% and $99.5 \%$, respectively), porous cylindrical $\mathrm{Au}-\mathrm{ZnO}$ heterostructure (95.3\% and $93.4 \%$, respectively) and pure $\mathrm{ZnO}$ (55.3\% and $40.7 \%$, respectively). It is well known that the photocatalytic activity is mainly determined by the phase structure, adsorption ability, and separation efficiency of photogenerated electrons and holes. As Au and $\mathrm{ZnO}$ contact each other, electrons in the $\mathrm{ZnO}$ migrate to the conduction band of the Au and generate a shortstop Schottky barrier at the interface of the two materials ${ }^{49}$ thus, the Au- $\mathrm{ZnO}$ composites exhibited higher photocatalytic activity than that of the pure $\mathrm{ZnO}$. In addition, the honeycomb $\mathrm{Au}-\mathrm{ZnO}$ heterostructure had a higher $\mathrm{Au}$ content, surface area and surface $\mathrm{O}_{\mathrm{V}}$ than those of the porous cylindrical $\mathrm{Au}-\mathrm{ZnO}$ heterostructure, which enabled its relatively high catalytic properties.

Mechanism. As shown in Fig. 8, a possible mechanism for the Au-ZnO catalyst behaviour is proposed. Under direct sunlight, excited electrons from the $\mathrm{ZnO}$ surface are driven to the Au nanoparticles because they have a stronger electron capture capability than that of the $\mathrm{ZnO}$. The excited electrons combine with $\mathrm{O}_{2}$ and form $\bullet \mathrm{O}_{2}{ }^{-}$ on the surface of Au nanoparticles ${ }^{50}$. Furthermore, the electron transfer facilitates the formation of holes $\left(\mathrm{H}^{+}\right)$ on the $\mathrm{ZnO}$ surface, leading to the production of $\bullet \mathrm{OH}$. Both $\bullet \mathrm{O}_{2}{ }^{-}$and $\bullet \mathrm{OH}$ are active substances for degrading organic dyes, which results in a significant enhancement in the catalytic activity ${ }^{51,52}$. In addition, the unique honeycomb and cylindrical structures with holes contribute to the large surface area, guaranteeing full contact between the light and $\mathrm{RhB}$. Therefore, the catalytic activity is further enhanced. The pore structures also provide the organic dyes and catalysts with pathways in and out, which greatly accelerates the reaction ${ }^{53,54}$. Finally, the honeycomb and porous cylindrical structures allow multiple reflections of solar light, which enhances the light harvesting and increases the distance of the photogenerated electrons and holes, which greatly enhances the catalytic properties of the samples.

\section{Conclusion}

In summary, honeycomb and porous cylindrical $\mathrm{Au}-\mathrm{ZnO}$ heterostructures were obtained through a straightforward, cost-effective and uncomplicated hydrothermal method. A possible formation and degradation mechanism were proposed. The two new heterostructures created a high surface area and multiple sunlight reactions via special pore structures, which resulted in their decreased PL intensity and enhanced degradation efficiency. Owing to the relatively high $\mathrm{Au}$ concentration and surface area, the honeycomb $\mathrm{Au}-\mathrm{ZnO}$ heterostructures exhibited weaker $\mathrm{PL}$ intensities and higher degradation efficiencies than those of the porous cylindrical $\mathrm{Au}-\mathrm{ZnO}$ heterostructures. With the honeycomb Au-ZnO catalyst, the RhB and MG solutions were almost completely degraded after $32 \mathrm{~min}$. It is expected that the $\mathrm{Au}-\mathrm{ZnO}$ heterostructures may have various technological applications, such as in photocatalysts, solar energy conversion and environmental purification.

Received: 10 April 2019; Accepted: 29 October 2019;

Published online: 14 November 2019

\section{References}

1. Han, D. L. et al. Engineering Charge Transfer Characteristics in Hierarchical Cu $\mathrm{C}_{2} \mathrm{~S}$ QDs@ ZnO Nanoneedles with p-n Heterojunctions: Towards Highly Efficient and Recyclable Photocatalysts. Nanomaterials 9, 16 (2019).

2. Yang, J. H., Wang, J., Li, X. Y., Wang, D. D. \& Song, H. Optimized design of three-dimensional multi-shell Fe $\mathrm{O}_{4} / \mathrm{SiO}_{2} / \mathrm{ZnO} /$ ZnSemicrospheres with type II heterostructure for photocatalytic applications. Catal. Sci. Technol. 6, 4525-4534 (2016).

3. Chen, W. et al. Controllable growth of ZnO-ZnSe heterostructures for visible-light photocatalysis. Crystengcomm 16, $1201-1206$ (2014).

4. Xiang, C. M., Ying, D., Lin, Y. \& Bai, B. H. Energy transfer in plasmonic photocatalytic composites. Light-Sci. Appl. 5, e16017 (2016). 
5. Francesca, P., Katsuhiro, I. \& Kazushi, M. A visible light-driven plasmonic photocatalyst. Light-Sci. Appl. 3, e133 (2014).

6. Lu, Z. Y. et al. Magnetic functional heterojunction reactors with 3D specific recognition for selective photocatalysis and synergistic photodegradation in binary antibiotic solutions. J. Mater. Chem. A 7, 13986-14000 (2019).

7. Jamadi, O. et al. Edge-emitting polariton laser and amplifier based on a $\mathrm{ZnO}$ waveguide, Light-Sci. Appl. 7, 82 (2018).

8. Zhang, L. et al. Significantly Enhanced Photocatalytic Activities and Charge Separation Mechanism of Pd-Decorated ZnO-Graphene Oxide Nanocomposites. ACS Appl. Mater. Inter. 6, 3623-3629 (2014).

9. Lu, L. et al. A fiber optoacoustic guide with augmented reality for precision breast-conserving surgery, Light-Sci. Appl. 7, 2 (2018).

10. Pawan, K. S., Young, T. C. \& Daping, C. A high-resolution optically addressed spatial light modulator based on ZnO nanoparticles, Light-Sci. Appl. 4, e259 (2015).

11. Gu, C. D. et al. Growth and Photocatalytic Activity of Dendrite-like ZnO@Ag Heterostructure Nanocrystals. Crystal Growth Des. 9, 3278-3285 (2009).

12. Han, D. L. et al. Engineering charge transfer characteristics in hierarchical $\mathrm{Cu}_{2} \mathrm{~S} Q D$ s @ $\mathrm{ZnO}$ nanoneedles with p-n heterojunctions: towards highly efficient and recyclable photocatalysts. Nanomaterials 9,16 (2019).

13. Ranjith, K. S., Senthamizhan, A., Balusamya, B. \& Uyar, T. Nanograined surface shell wall controlled ZnO-ZnS core-shell nanofibers and their shell wall thickness dependent visible photocatalytic properties. Catal. Sci. Technology 7, 1167-1180 (2017).

14. Wu, F., Tian, L. M., Kanjolia, R., Singamaneni, S. \& Banerjee, P. Plasmonic Metal-to-Semiconductor Switching in Au Nanorod-ZnO nanocomposite films. ACS Appl. Mater. Inter. 5, 7693-7697 (2013).

15. Cheng, Y. F. et al. Two Hybrid Au-ZnO Aggregates with Different Hierarchical Structures: a Comparable Study in Photocatalysis. J. Colloid Interf. Sci. 509, 58-67 (2018).

16. Demille, T. B. et al. Light-Mediated Growth of Noble Metal Nanostructures (Au, Ag, Cu, Pt, Pd, Ru, Ir, Rh) From Micro- and Nanoscale ZnO Tetrapodal Backbones. Front. Chem. 6, 411 (2018).

17. She, P. et al. $\mathrm{ZnO}$ nanodisks decorated with Au nanorods for enhanced photocurrent generation and photocatalytic activity. New J. Chem. 42, 3315-3321 (2018).

18. Guria, M. K., Majumdar, M. \& Bhattacharyya, M. Green synthesis of protein capped nano-gold particle: An excellent recyclable nano-catalyst for the reduction of nitro-aromatic pollutants at higher concentration. Powder Technol. 222, 549-557 (2016).

19. Sinha, G., Depero, L. E. \& Alessandri, I. Recyclable SERS Substrates Based on Au-Coated ZnO Nanorods. ACS Appl. Mater. Interfaces 3, 2557-2563 (2011).

20. Li, P., Wei, Z., Wu, T., Peng, Q. \& Li, Y. Au-ZnO Hybrid Nanopyramids and Their Photocatalytic Properties. J. Am. Chem. Soc. 133, $5660-5663(2011)$

21. Mahanti, M. \& Basak, D. Enhanced ultraviolet photoresponse in Au/ZnO nanorods. Chem. Phys. Lett. 612, 101-105 (2014).

22. Karabchevsky, A., Mosayyebi, A. \& Kavokin, A. V. Tuning the chemiluminescence of a luminol flow using plasmonic nanoparticles. Light-Sci. Appl. 5, e16052 (2016).

23. Li, D. et al. Supra-(carbon nanodots) with a strong visible to near-infrared absorption band and efficient photothermal conversion. Light-Sci. Appl. 5, e16120 (2016)

24. Kuriakose, S. et al. Facile synthesis of Au-ZnO plasmonic nanohybrids for highly efficient photocatalytic degradation of methylene blue. Powder Technol. 64, 47-52 (2017).

25. Yu, X. J., Liu, F. Z., Bi, J. L., Wang, B. \& Yang, S. C. Improving the plasmonic efficiency of the Au nanorod-semiconductor photocatalysis toward water reduction by constructing a unique hot-dog nanostructure. Nano Energy 33, 469-475 (2017).

26. Hou, X. M. Nonaqueous fabrication of $\mathrm{ZnO} / \mathrm{Au}$ nanohybrids with enhanced photocatalytic activity. Mater. Lett. 137, 319-322 (2014).

27. Zanella, R., Giorgio, S., Henry, C. R. \& Louis, C. Alternative Methods for the Preparation of Gold Nanoparticles Supported on TiOI r. J. Phys. Chem. B 106, 7634-7642 (2002).

28. Bailie, J. E. et al. Hydrogenation of but-2-enal over supported $\mathrm{Au} / \mathrm{ZnO}$ catalysts. Phys. Chem. 3, 4113-4121 (2001).

29. Geng, J., Song, G. H., Jia, X. D., Cheng, F. F. \& Zhu, J. J. Fast One-Step Synthesis of Biocompatible ZnO/Au Nanocomposites with Hollow Doughnut-Like and Other Controlled Morphologies. J. Phys. Chem. C 116, 4517-4525 (2012).

30. Chen, Y. Z. et al. Au-ZnO hybrid nanoflowers, nanomultipods and nanopyramids: One-pot reaction synthesis and photocatalytic properties. Nanoscale 6, 874-881 (2014).

31. Pattarasuda, N., Apanee, L. \& Sujitra, W. K. Preferential $\mathrm{CO}$ oxidation over $\mathrm{Au} / \mathrm{ZnO}$ and $\mathrm{Au} / \mathrm{ZnO}-\mathrm{Fe}_{2} \mathrm{O}_{3}$ catalysts prepared by photodeposition. Int. J. Hydrogen Energy. 34, 9838-9846 (2009).

32. Chen, B. D. et al. Hybrid nanostructures of Au nanocrystals and $\mathrm{ZnO}$ nanorods: Layer-by-layer assembly and tunable blue-shift band gap emission. Mater. Res. Bull. 44, 889-892 (2009).

33. Yao, K. X., Liu, X., Zhao, L., Zeng, H. C. \& Han, Y. Site-specific growth of Au particles on ZnO nanopyramids under ultraviolet illumination. Nanoscale 3, 4195-4200 (2011).

34. Tripathy, N., Ahmad, R., Ko, H. A., Khanga, G. \& Hahn, Y. B. Multi-synergetic ZnO platform for high performance cancer therapy. Chem. Commun. 51, 2585 (2015).

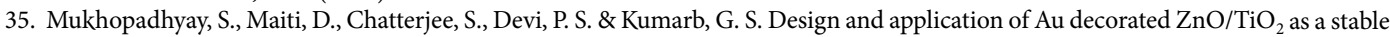
photocatalyst for wide spectral Coverage. Phys. Chem. Chem. Phys 18, 31622-31633 (2016).

36. Li, Z. X. et al. Novel porous carbon nanosheet derived from a 2D Cu-MOF: Ultrahigh porosity and excellent performances in the supercapacitor cell. Carbon 144, 540-548 (2019).

37. Zhang, H. B., Jin, S. W., Duan, G. T., Wang, J. J. \& Cai, W. P. Controllable Synthesis of Well-aligned ZnO Nanorod Arrays on Varying Substrates via Rapid Electrodeposition. J. Mater. Sci. Technol. 30, 1118-1123 (2014).

38. De-Zhi, W. U., Fan, X. M. \& Tian, K. Fabrication and photocatalytic properties of Cu2S/T-ZnO w heterostructures via simple polyol process. T. Nonferr. Metal. Soc. 22, 1620-1628 (2012).

39. Han, D., Cao, J. \& Yang, S. Investigation of composition dependent structural and optical properties of the $\mathrm{Zn}_{(1-x)} \mathrm{Cd}_{(\mathrm{x})} \mathrm{S}$, coaxial $\mathrm{Zn}_{(0.99-\mathrm{x})} \mathrm{Cd}_{(\mathrm{x})} \mathrm{Cu}_{(0.01)} \mathrm{S} / \mathrm{ZnS}, \mathrm{Zn}_{(0.99-\mathrm{x})} \mathrm{Cd}_{(\mathrm{x})} \mathrm{Mn}_{(0.01)} \mathrm{S}$ nanorods generated by a one-step hydrothermal process. Dalton T. 43, $11019-11026$ (2014).

40. Kima, K. J., Kreider, P. B., Chang, C. H., Park, C. M. \& Ahn, H. G. Visible-light-sensitive nanoscale Au-ZnO photocatalysts. J. Nanopart. Res. 15, 1606 (2013).

41. Chen, D. M. et al. Influence of Defects on the Photocatalytic Activity of ZnO. J. Phys. Chem. C 118, 15300-15307 (2014).

42. Zhang, X., Wang, Y. \& Hou, F. Effects of Ag loading on structural and photocatalytic properties of flower-like ZnO microspheres. Appl. Surf. Sci. 391, 476-483 (2017).

43. Kamarulzaman, N., Kasim, M. F. \& Chayed, N. F. Elucidation of the highest valence band and lowest conduction band shifts using XPS for $\mathrm{ZnO}$ and $\mathrm{Zn} 0.99 \mathrm{Cu} 0.01 \mathrm{O}$ band gap changes. Results. Phy. 6, 217-230 (2016).

44. Hsu, N. F., Chung, T. K., Chang, M. \& Chen, H. J. Rapid Synthesis of Piezoelectric ZnO-Nanostructures for Micro Power-Generators. J. Mater. Sci. Technol. 29, 893-897 (2013).

45. Wang, Z., Qian, X. F., Yin, J. \& Zhu, Z. K. Large-Scale Fabrication of Tower-like, Flower-like, and Tube-like ZnO Arrays by a Simple Chemical Solution Route. Langmuir 20, 3441-3446 (2004).

46. Yang, Y. C. et al. Polypyrrole-Decorated $\mathrm{Ag}-\mathrm{TiO}_{2}$ Nanofibers Exhibiting Enhanced Photocatalytic Activity under Visible-Light Illumination, ACS. Appl. Mater. Inter. 5, 6201-6207 (2013).

47. Zhu, W. W., Chen, J. C., Hao, C. Y. \& Zhang, J. S. Microstructure and Strength of $\mathrm{Al}_{2} \mathrm{O}_{3} / \mathrm{Al}_{2} \mathrm{O}_{3}$ Joints Bonded with $\mathrm{ZnO}-\mathrm{Al}_{2} \mathrm{O}_{3}-\mathrm{B}_{2} \mathrm{O}_{3}-\mathrm{SiO}_{2}$ Glass-Ceramic. J. Mater. Sci. Technol. 30, 944-948 (2014). 
48. De Lourdes Ruiz Peralta, M., Pal, U. \& Sánchez Zeferino, R. Photoluminescence (PL) Quenching and Enhanced Photocatalytic Activity of Au-Decorated ZnO Nanorods Fabricated through Microwave-Assisted Chemical Synthesis. ACS Appl. Mater. Inter. 4, 4807-4816 (2012).

49. Su, L. \& Qin, N. A facile method for fabricating Au-nanoparticles-decorated $\mathrm{ZnO}$ nanorods with greatly enhanced near-band-edge emission. Ceram. Int. 41, 2673-2679 (2015).

50. Yu, J. G., Yue, L., Liu, S. W., Huang, B. B. \& Zhang, X. Y. Hydrothermal preparation and photocatalytic activity of mesoporous $\mathrm{Au}-\mathrm{TiO}_{2}$ nanocomposite microspheres. J. Colloid Inter. Sci. 334, 58-64 (2009).

51. Hou, X. G., Huang, M. D., Wu, X. L. \& Liu, A. D. Preparation and studies of photocatalytic silver-loaded TiO2 films by hybrid sol-gel method. Chem. Eng. J. 146, 42-48 (2009).

52. Pugaze, R. et al. Room Temperature Ferromagnetism in Dual Doped $\left(\mathrm{Mn}^{2+}, \mathrm{Ni}^{2+}\right) \mathrm{ZnO}$ Codoped with $\mathrm{Li}^{1+}$ Prepared Using EDTA Sintered at Low Temperature. J. Mater. Sci. Technol. 30, 275-279 (2014).

53. Zhang, M. Y. et al. Core-shell structured Si/ZnO photovoltaics. Mater. Lett. 140, 59-63 (2015).

54. Yu, J. G., Yu, X. X., Huang, B. B., Zhang, X. Y. \& Dai, Y. Hydrothermal Synthesis and Visible-light Photocatalytic Activity of Novel Cage-like Ferric Oxide Hollow Spheres. Cryst. Growth. Des. 9, 1474-1480 (2009).

\section{Acknowledgements}

Financial support for this work was provided by the China Postdoctoral Science Foundation [Grant Number 2017M621645]; Postdoctoral Funds of Jiangsu Province [Grant Numbers 1701103B and 1701106B]; the Natural Science Foundation of Jiangsu Province [Grant Number BK20180880]; and the National Natural Science Foundation of China [Grant Number 21676115 and 61705020].

\section{Author contributions}

S.Y. and D.H. carried out the samples synthesis experiments and wrote the main manuscript text; L.J. Wang discussed Figures 2(b,d) and 4 and re-drawn Figures 1-3 and 7-8; Z.L. prepared Figure 1; L.Y. prepared Figures 2(a,c) and 3; J.Z. prepared Figures 2(b,d) and 4; X.L. carried out the photocatalysis organic degradation experiments using malachite green (MG); Y.Y. and P.H. reviewed the manuscript and prepared Figure 6; and S.Y. and D.H. acquired the funding. All authors reviewed the manuscript.

\section{Competing interests}

The authors declare no competing interests.

\section{Additional information}

Correspondence and requests for materials should be addressed to D.H. or P.H.

Reprints and permissions information is available at www.nature.com/reprints.

Publisher's note Springer Nature remains neutral with regard to jurisdictional claims in published maps and institutional affiliations.

(c) (i) Open Access This article is licensed under a Creative Commons Attribution 4.0 International License, which permits use, sharing, adaptation, distribution and reproduction in any medium or format, as long as you give appropriate credit to the original author(s) and the source, provide a link to the Creative Commons license, and indicate if changes were made. The images or other third party material in this article are included in the article's Creative Commons license, unless indicated otherwise in a credit line to the material. If material is not included in the article's Creative Commons license and your intended use is not permitted by statutory regulation or exceeds the permitted use, you will need to obtain permission directly from the copyright holder. To view a copy of this license, visit http://creativecommons.org/licenses/by/4.0/.

(C) The Author(s) 2019 